\title{
Reporter's Privilege and Incentives to Leak
}

\author{
IDO BAUM, EBERHARD FEESS, ANSGAR WOHLSCHLEGEL ${ }^{*}$ \\ College of Management School of Law, Rishon Le Zion, Israel; \\ Frankfurt School of Finance \& Management, Germany; University of Bonn, Germany
}

Journalists sued for defamation may refuse to reveal their anonymous sources. To escape liability under the traditional English rule, they then need to show proof that the news is correct. By contrast, many US states have switched the burden of proof such that plaintiffs must first present evidence that the news is false. Focusing on the incentives of sources to leak, we find that the American rule reduces the frequency of type I errors (true stories are not learned by the society) at the expense of a bigher frequency of type II errors (the society believes wrong stories). The American rule is superior when courts are likely to find the truth without knowing the identity of sources, and when firms can severely punish even honest sources. Furthermore, when courts rule that sources must be revealed, they should ensure a higher compliance rate of journalists under the American rule.

\section{INTRODUCTION}

\subsection{Motivation AND Main Results}

Political and corporate scandals reported by the media often rely on insider information provided by sources having a vital interest in keeping their identity in the dark. To protect confidential sources, legal systems empower the press with a testimonial privilege. This privilege exists in all democratic societies, but the design of defamation law is strikingly different in the US and in Europe. Under the traditional English System applied in the EU, Canada and Australia, a journalist sued for defamation bears the burden of proof that the allegedly defamatory information he has published is true or that he has taken due care in trying to identify wrong stories. ${ }^{1}$ In the US, many courts switched the burden of

\footnotetext{
* The authors are grateful to an anonymous referee for helpful suggestions.

${ }^{1}$ See, e.g., Williams (1997) and Kenyon (2004a, 2004b) for Australia. In Canada (Hill v. Church of Scientology of Toronto, 1995), the Supreme Court of Canada supported the English Rule by
} 
proof such that the plaintiff must first provide evidence that the news is false in order to proceed with the claim. ${ }^{2}$ Consequently, courts in the US have gone as far as refusing to honor defamation damages awarded by English courts. ${ }^{3}$

The objective of defamation law is twofold: On the one hand, publication of true stories needs to be encouraged, and it needs to be avoided that journalists must withdraw true stories in the courtroom. On the other hand, making up wrong stories needs to be discouraged, and when made up, wrong stories should not be upheld during litigation. We will speak of type I errors when the public does not learn true stories, and of type II errors if the public mistakenly believes wrong stories. Situations we have in mind include any kind of negative information that firms may want to hide from shareholders, for instance corruption or product liability risks, but our analysis obviously extends to any kind of wrongdoing.

When analyzing the trade-off between type I and type II errors, we focus on the incentives of sources to leak, and we model the difference between the English and the American rule in a very simple way: under the English rule, we assume that journalists sued for defamation first need to present evidence that the story is actually true, and we further assume that the court will never believe them when the identity of sources is kept in the dark. This seems strict as, in reality, journalists can also escape liability by proving that they took due care, but all we need is that revealing sources decreases the liability risk.

The reversal of the burden of proof under the American rule is modelled by assuming that firms first need to present evidence indicating that the story is false. If the court accepts the firms' proposals of opening a file, journalists can again not escape liability without revealing their sources, and the situation is then the same as under the English rule. However, when the court rejects the firms' proposals, journalists will not be interrogated by the court, and sources can be sure that their identities are treated confidentially. Of course, there are also important procedural differences between the English and the American rule, but the reversal in the burden of proof has always been considered as crucial to enforce the reporter's privilege.

Since revelation of sources increases the probability of finding the truth, it is obvious that the English rule is ex post superior, i.e. it outperforms the American rule given that a story has already been leaked. With respect to ex ante efficiency, however, a trade-off arises. Since sources will less often be revealed, the American

arguing that imposing the burden of proof on journalists does not contradict the constitutional protection of freedom of speech in the Charter.

2 In Philadelphia Newspapers v. Hepps (1986), the US Supreme Court completed its departure from English defamation Law when it held that putting the burden of proof on the media would be unconstitutional (see Gatley, 2004).

3 See, e.g., Bachchan v. India Abroad Publications Inc. (1992). 
rule sets higher incentives to leak both true and wrong stories, and thereby leads to a lower frequency of type I errors, but to a higher frequency of type II errors.

To analyze the impact of important factors on this trade-off (and hence on the ranking of the two rules), we consider a simple model where only sources are treated as strategic players, while the behavior of firms and journalists is not modelled explicitly. We first find that the American rule is superior when the probability of finding the truth even without knowing the identity of sources is sufficiently high. Second, the American rule is superior when the informal punishment potential of firms is high even for honest sources. ${ }^{4}$

In an extension of our basic model, we assume that legislators can influence the journalists' willingness to reveal confidential sources, which we refer to as "compliance rate," by the design of liability rules (for instance by the amount of damages or by the definition of due care). We then find that courts should put higher pressure on journalists under the American rule because the allocation of the burden of proof and the pressure on journalists to reveal sources given that they are asked to do so can be considered as substitutes. Under the English rule, the burden of proof is imposed on journalists, and imposing high damages in addition would reinforce the chilling effect of the English rule in an inefficient way.

\subsection{RELATION TO THE LITERATURE}

There are many papers which summarize the differences between the American and the English rule from a legal point of view and which comment on the most important decisions (see, e.g., Gilles, 1998; Bruns, 2000; Docherty, 2000; Loveland, 2003; Gatley, 2004; and Teeter et al., 2004). In particular, Berlins (2004) and Browne (2005) point to the chilling effect of the English, and Dent and Kenyon (2004), Marjoribanks and Kenyon (2004) and Weaver and Partlett (2004) confirm that the media is reluctant to publish stories based on testimonies of anonymous sources in Australia. Kirtley (1996), Dienes et al. (1999) and Bruns (2000) focus on procedural differences such as pre-trial inquiries, but they also share our view that the allocation of the burden of proof is the main difference between the English and the American rule.

The starting point of almost all economic papers on defamation law is that only part of the social value from publishing true stories can be captured by the media itself. This suggests a rather "soft" liability rule that encourages publications by adopting either low standards of due care, by reducing damages, or by switching the burden of proof to the plaintiff as under the American rule (see, e.g., Sheer and Zardkoohi, 1985, 1989; Hollander, 1989; Anderson, 1991; and Bradley, 1996).

These arguments are reasonable with respect to the journalists' decisions to publish, but they neglect the incentives to identify wrong stories. Taking both

${ }^{4}$ Those informal punishments may consist of reduced promotion opportunities, for instance.

DOI: $10.2202 / 1555-5879.1367$ 
decisions into consideration, Bar-Gill and Hamdani (2003) show that second best optimal incentives can be implemented by setting damages equal to the difference between the benefits from publishing true stories and the social loss from publishing wrong stories. In two companion papers, Garoupa (1999a, 1999b) also analyzes liability regimes leading to second best incentives for journalists when they are only imperfectly informed about the facts to be published (in his case, the dishonesty of politicians). Most recently, Dalvi and Refalo (2008) argue that liability rules for journalists based on negligence are likely to be inferior to strict liability because they reduce the differences of being held liable when publishing wrong and true stories, as exerting due care exonerates from liability even when the story is wrong.

The papers just mentioned derive interesting results, but they all focus on the incentives of the media to publish and to investigate stories rather than the incentives to protect confidential sources. By contrast, we are mainly interested in the impact of the two rules on the likelihood that anonymous sources are indeed protected in defamation suits, and hence on the incentives to leak stories in the first place.

As our paper is about the optimal allocation of the burden of proof, it is also related to a broader kind of literature. Topics in this literature include the optimal balance of type I and type II errors (see, e.g., Rubinfeld and Sappington, 1987; and Sanchirico, 1997), impacts of the allocation of proof on the incentives to disclose information (see, e.g., Shin, 1998; and Cooter and Emons, 2003) and on the ex ante incentives to take care (see Polinsky and Shavell, 1989; Bernardo et al., 2000; and Demougin and Fluet, 2006).

The remainder of the paper is organized as follows: section 2 presents the basic model and compares the American and the English rule. Section 3 extends to situations where journalists' willingness to reveal sources is endogenously determined by variables chosen by legislators, and section 4 concludes.

\section{BASIC MODEL}

In our model, stories leaked by confidential sources and published in the media reveal bad news about a company that is likely to negatively affect the value of the company's assets. Sources can leak stories which are effectively true, but they can also make up wrong stories. We normalize the numbers of both true and wrong stories to 1 each.

Inefficiencies on capital markets arise when true stories are not learned (type I errors) or when wrong stories are believed by capital markets (type II errors). Type I errors occur when true stories are not published at all, or when they must be withdrawn after a defamation suit. Similarly, type II errors arise when 
wrong stories are published and upheld in the courtroom. Whether social costs are higher for type I or type II errors may vary from case to case, so that we allow for both cases by normalizing costs of type I errors to 1 and by denoting social costs of type II errors by $\tau \in(0, \infty)$.

Sources will leak stories if and only if their private benefits are weakly above their expected costs from being disclosed in defamation suits. We assume that benefits differ among sources and are uniformly distributed on $\alpha \in(0,1)$. Private costs of sources when their identity is revealed are denoted by $t$ and assumed to be positive even in cases where the story is upheld by the court. These costs capture the informal punishment potential of firms against honest sources, for instance, the costs of losing promotion opportunities. When a story is judged as being wrong such that sources are found to be dishonest, private costs are clearly higher and denoted by $w \in(t, 1)$.

The social benefit of revealing sources in defamation suits is that it reduces the probability of misjudgments, and this information value is modeled in the simplest way by assuming that courts (and hence capital markets) always learn the truth when sources are revealed. Otherwise, decisions are correct with probability $q>0.5$, and wrong with probability $1-q$.

To keep things simple, we assume that journalists publish all stories they get, and that they reveal their anonymous sources with some exogenously given probability $\pi$ when the court orders them to do so. Since $\pi$ is the probability that journalists follow the court's order, we will refer to it as the compliance rate. Of course, journalists will reveal in a specific case if and only if the (reputation) costs of revelation are below the expected reduction in damages. Assuming that the compliance rate is exogenous and identical for the American and the English Rule serves as a useful benchmark, but we will endogenize it in section 3. Note carefully that, even though we assume the same compliance rate for both legal rules, the equilibrium revelation frequency will differ, as it depends on bow often journalists will actually be asked to reveal their sources.

The key difference between the two legal rules is the allocation of the burden of proof, and we capture this by the sequence of the game: Under the American rule, firms suing for defamation must first present their evidence, and the court will ask journalists to reveal their sources only if it accepts the firms' evidence in the first place. By contrast, the burden of proof is allocated to journalists under the English rule, and we model this by assuming that the court first demands that journalists reveal their sources. Furthermore, we assume that, under both rules, journalists refusing to reveal their sources will always lose defamation suits. In reality, journalists can also win defamation suits without revealing their sources, but all we need for our analysis is that revelation reduces expected damages, and this is clearly realistic. Finally, we assume that all firms sue for defamation.

DOI: $10.2202 / 1555-5879.1367$ 


\subsection{ENGLISH RULE}

True stories. We now start our analysis with the English rule. Consider first sources having true stories who know that firms will sue for defamation. If journalists refuse to reveal, private costs are zero. With revelation, the court always comes to the correct decision, and the private costs from informal punishments of firms are thus $t$. It follows that expected costs are $\pi t$ so that sources will leak true stories if their private benefits are (weakly) above the critical threshold $\alpha_{t}^{E}:=\pi t .{ }^{5}$ And as $\alpha$ is uniformly distributed on $(0,1)$, the percentage of true stories leaked is $L_{t}^{E}=1-\pi t$.

Expected social costs of type I errors are thus

$$
\phi_{1}^{E}=\pi t+(1-\pi t)(1-\pi)(1-q):
$$

With probability $1-L_{t}^{E}=\pi t$, true stories are not leaked, and capital markets do not get the valuable information. If they are leaked and hence published (which happens with probability $1-\pi t$ ), journalists refuse to disclose with probability $1-\pi$, and courts then err with probability $1-q$.

Wrong stories. For similar reasons, wrong stories are leaked if $\alpha \geq \alpha_{w}^{E}:=\pi w$, since sources will always be identified as dishonest when their identity is disclosed. The percentage of wrong stories leaked is thus $L_{w}^{E}=1-\pi w$.

Expected social costs of type II errors are

$$
\phi_{2}^{E}=\tau(1-\pi w)(1-\pi)(1-q):
$$

With probability $L_{w}^{E}=1-\pi w$, wrong stories are made up, and they are not corrected with probability $1-q$ if and only if journalists refuse to reveal sources (which happens with probability $1-\pi$ ).

\footnotetext{
${ }^{5}$ Subscript " $t$ " denotes true stories and " $E$ " stands for the English rule.
} 
Reporter's Privilege and Incentives to Leak / 707

\subsection{AMERICAN RULE}

True stories. Sources having true stories know that firms first need to present evidence, and that courts will proceed with defamation suits with probability $1-q$. Journalists will then disclose with probability $\pi$, and since courts will then find the truth, sources bear punishment costs of $t$. It follows that true stories are leaked iff $\alpha \geq \alpha_{t}^{A}:=(1-q) \pi t$, so that the percentage of true stories leaked is $L_{t}^{A}=1-(1-q) \pi t$.

Expected social costs of type I errors are

$$
\phi_{1}^{A}=(1-q) \pi t+(1-(1-q) \pi t)(1-q)(1-\pi):
$$

With probability $1-L_{t}^{A}=(1-q) \pi t$, honest sources don't leak. With the counter probability $(1-(1-q) \pi t)$, true stories are published, but wrong judgments are made with probability $(1-q)$ if and only if journalists protect their sources (which happens with probability $1-\pi$ ).

Wrong stories. For similar reasons, we get $\alpha_{w}^{A}:=q \pi w, L_{w}^{A}=1-q \pi w$, and social costs of type II errors are

$$
\phi_{2}^{A}=\tau(1-q \pi w)(1-q):
$$

Wrong stories are leaked with probability $L_{w}^{A}=(1-q \pi t)$, and they are mistakenly believed by courts with probability $(1-q)$. Note that the game ends when the court does not accept the firms' files, so that there is no revelation decision to be made by the journalist. This is exactly why the burden of proof matters even though we assume that $\pi$ is identical under both systems and that courts certainly find the truth when sources are revealed. ${ }^{6}$

Note that when courts correctly believe firms, the journalists' revelation decisions have no impact on the frequency of type II errors. If journalists reveal, courts find out that the story is wrong, and otherwise they keep thinking that the story is wrong anyway.

\subsection{COMPARISON OF THE TWO RULES}

First of all, it is straightforward that the English rule dominates the American rule ex post, i.e. whenever a story is already published. The reason is that allocating the burden of proof to journalists leads to a higher revelation frequency, thereby reducing the risk of misjudgments. However, we also need to take the ex ante incentives of sources into account in order to compare the overall

\footnotetext{
6 Assuming instead that courts err with some probability $\xi<1-q$ even when sources are disclosed, our results remain qualitatively unchanged.
}

DOI: $10.2202 / 1555-5879.1367$ 
probabilities that capital markets will get wrong information. We first consider type I and type II errors separately, and then proceed to an overall comparison.

True stories (Type I errors). Given that true stories are leaked, the error risk is the same under both rules. Under the English rule, misjudgments occur if and only if journalists do not reveal and courts err, while under the American rule, misjudgments arise when courts open the file and journalists do not reveal. Hence, the allocation of the burden of proof has no impact on type I errors when true stories are published. However, true stories will be leaked less often under the English rule as sources bear higher risks of being revealed. This captures the chilling effect of the English rule and leads to a higher frequency of type I errors. Formally, the difference in social costs of type I errors is

$$
\Delta_{1} \equiv \phi_{1}^{E}-\phi_{1}^{A}=\operatorname{tq} \pi(\pi+q(1-\pi))>0 .
$$

From the partial derivatives, it is easily seen that the advantage of the American rule in avoiding type I errors is increasing in $\pi, t$ and $q$ : The higher the revelation probability $\pi$ and the higher the negative consequences of being revealed captured by $t$, the more pronounced is the chilling effect of the English rule. And if $q$ is increasing, then capital markets are more likely to learn true stories even without revelation of sources, and the expost inefficiency of the American rule then becomes less important compared to the ex ante inefficiencies of the English rule.

Wrong stories (Type II errors). For wrong stories, the English rule is superior for two reasons: first, the leakage frequency is again lower, since sources bear higher risks that their identities are revealed. Second, the percentage of misjudgments by courts is lower as all files are opened. Formally, the difference in social costs of type II errors is

$$
\Delta_{2} \equiv \phi_{2}^{E}-\phi_{2}^{A}=-\tau \pi(1-q)(1+w(1-\pi-q))<0 .
$$

As we consider wrong stories where chilling effects are good news, the advantage of the English rule is now increasing in $\pi$. Furthermore, it decreases in $q$ as the disclosure of sources becomes less important when courts are likely to come to correct decisions even without learning their identity. Finally, the impact of $w$ is ambiguous due to the following countervailing effects: On the one hand, the marginal chilling effect of $w$ on the leakage probability is higher under the English rule ( $-\pi$ compared to $-q \pi)$. But on the other hand, this marginal impact needs to be weighted with the probability that capital markets 
actually believe wrong stories given that they are leaked, and this probability is lower under the English rule, which makes the overall comparison ambiguous. ${ }^{7}$

Overall comparison. Our simple model supports the intuition that the English rule discourages leaking of both true and wrong stories, and hence leads to a lower frequency of type II errors at the expense of a higher frequency of type I errors. Of course, this implies that the English rule tends to be superior if $\tau$ is high, i.e. when type II errors are more important than type I errors. Besides this obvious feature, an overall comparison of the two rules yields the following insights:

First, a higher accuracy of judgments without revelation of sources as measured by $q$ supports the American rule: it increases its advantage in avoiding type I errors, and it decreases its disadvantage of producing more type II errors. Thus, the burden of proof should be imposed on journalists if and only if knowing the identity of sources is sufficiently valuable. In particular, the American rule is always superior when $q$ is sufficiently high, and it will be inferior otherwise when type II errors are very important (see result 1 below).

Second, recall that in our model courts always come to correct decisions when sources are revealed. Hence, the punishment potential of firms in case of true stories $(t)$ affects only the incentives to leak true stories, and we have seen that the advantage of the American rule concerning the leaking of true stories becomes more pronounced if $t$ is high. For $t \rightarrow 0$, the English rule is superior regardless of the relative importance of type I and type II errors, as all true stories will be leaked anyway, and because the chilling effect on wrong stories is higher. For the maximum $t \rightarrow w$, however, the ranking depends on the relative importance of the two error types. It follows that the burden of proof should be imposed on journalists when legal systems (for instance, the institutions on labor markets) strongly protect honest sources from informal punishments. Furthermore, societies should invest more to protect honest sources when the English rule is applied as $t$ is more important. There are no clear-cut results for the impact of the punishment potential on dishonest sources captured by $w$ due to the countervailing effects described above. We summarize in

Result 1. Suppose the willingness of a journalist to reveal his sources if the court orders him to do so $(\pi)$ is exogenously given and identical under both rules. Then, (i) the English rule leads to more type I errors, but to less type II errors. (ii) The relative advantage of the American

\footnotetext{
${ }^{7}$ Formally, the influence of $w$ on the difference in social costs of type II errors is $-\tau \pi(1-q)$ $(1-\pi-q)$ which is negative if and only if $\pi+q<1$. That is to say, if $\pi+q<1$, then the advantage of the English rule is increasing in the source's private costs of being found to have leaked a wrong story.
}

DOI: $10.2202 / 1555-5879.1367$ 
rule is increasing in $q$. When $q$ is sufficiently high, then the American rule is superior regardless of the relative importance of the two error types. (iii) The relative advantage of the American rule is increasing in $t$. For the minimum $t \rightarrow 0$, the English rule is always superior. For the maximum $t \rightarrow w$, the ranking is ambiguous.

\section{EXTENDING THE BASIC MODEL: COMPLIANCE RATE CHOSEN BY LEGISLATORS}

In our basic model, we have assumed that the compliance rate $\pi$ is exogenously given and identical under both systems. In reality, however, $\pi$ depends on many factors like preference costs from breaking promises, negative reputation effects in acquiring new sources, the newspaper's corporate policy, and, most notably, on variables chosen by legislators as the relative probabilities of being held liable with and without revealing sources and damages when being held liable. To account for this, we now assume that $\pi$ is chosen by legislators so as to minimize social costs given by

$$
S C=\phi_{1}^{i}+\phi_{2}^{i}, i=E, A .
$$

Of course, the optimal compliance rate will then differ under the two legal rules.

English rule. Under the English rule, the frequency of type II errors is strictly decreasing in $\pi$, as a higher compliance rate reduces both the incentives to make up wrong stories and the risk of misjudgments when wrong stories are published. The impact of $\pi$ on type I errors, however, is ambiguous. On the one hand, a higher $\pi$ may deter more sources from leaking true stories, but given that a story is leaked, no mistakes will be made when sources are revealed. This captures in a simple way the trade-off between ex ante and expost efficiency for type I errors.

When the frequency of type I errors is decreasing in $\pi$, then it is obviously optimal to implement a compliance rate of $\pi=1$ as both error types are decreasing in $\pi$. Otherwise, there is an interior solution where the optimal compliance rate denoted $\pi^{E}$ depends on $\tau$, i.e. on the relative importance of the two error types.

American rule. For similar reasons, the frequency of type II errors is strictly decreasing in the compliance rate, while the impact of $\pi$ on type I errors is ambiguous. Hence, $\pi=1$ may again be optimal, but an interior solution for $\pi^{A}$ arises when the frequency of type I errors is increasing in $\pi$. 
Comparison. Comparing the two rules yields the following result:

Result 2. Suppose the compliance rate $\pi$ can be chosen by legislators. Then, if there are interior solutions for $\pi^{i}, i=E, A$, the optimal compliance rate is strictly higher under the American rule, i.e. $\pi^{A}>\pi^{E}$.

Result 2 is derived in the Appendix, and shows that the allocation of the burden of proof and the optimal compliance rate of journalists in revealing their confidential sources can be interpreted as substitutes in the legal design of defamation suits: Due to the allocation of the burden of proof, journalists will less often be required to reveal their confidential sources under the American rule. This leads to relatively high incentives to make up wrong stories (and hence to many type II errors) and needs to be countervailed by a high compliance rate if courts actually rule that sources must be disclosed. By contrast, putting high pressure on journalists under the English rule would discourage even honest sources, and would hence lead to inefficiently many type I errors. Of course, both optimal compliance rates depend on the relative weight of the two error types (i.e., on $\tau$ ), but the main result that $\pi^{A}>\pi^{E}$ is robust with respect to variations in $\tau$.

A next natural question is which rule tends to be superior given that the compliance rate is optimally adjusted in either case. The comparison, however, depends in a complex way on all parameters of the model $(q, t$ and $w)$ and does not yield clear insights even for special assumptions about the relative importance of the two error types (for $\tau=1$, for instance). In addition, the comparative statics with respect to $q, t$ and $w$ also show that the ranking of the two rules cannot be attributed to single parameters only. Our main result from endogenizing $\pi$ is thus that, whenever courts want sources to be revealed at all, they should put higher pressure on journalists in order to increase their compliance rate under the American rule.

\section{CONCLUSION}

We have found that the American rule which allocates the burden of proof to plaintiffs is likely to cause less type I errors at the expense of more type II errors, which supports basic arguments about the chilling effects of the English rule. We have then focused on the impact different factors have on the relative frequency of type I and type II errors, and we have first shown that the American rule tends to be superior when courts are likely to come to correct decisions even without knowing the identity of sources. As a consequence, the allocation of the burden of proof according to the English or the American rule could be made dependent on the case at hand. For instance, it may often be easier for courts to collect sufficient evidence in cases of collusion where

DOI: $10.2202 / 1555-5879.1367$ 
the first information comes from an anonymous whistle-blower even without knowing the source's identity, whereas cases of corruption may require testimonial evidence to find the truth. Second, the American rule tends to outperform the English rule when firms can put high pressure on sources, and the rules can hence be related to legal rules on protections in labor markets.

In the early economic literature, the reversal of the burden of proof under the American rule and the weak due care level adopted in negligence rules for journalists has often been justified by assuming that the media's incentive to publish will be too small, as it can only appropriate part of the social utility from disclosing corporate or political scandals. In other words, the literature focuses on the difference in the social and the private costs of type I errors. Notwithstanding the fact that this difference may be important, our analysis highlights that the difference in the social loss from type I and type II errors may be more important when comparing the English to the American rule. Legislators need to balance the social costs of type I and type II errors at the margin, and we have found that in doing so the allocation of the burden of proof and factors influencing the willingness of journalists to reveal their anonymous sources can be considered to be substitutes.

The most important restriction of our analysis is that the behavior of both firms and journalists is not modelled explicitly. Hence, it is important to see whether the crucial factors identified in our paper are likely to survive in a more extended model where the strategic incentives of firms and the media are taken into account. We also analyzed such an extended model and found that firms' incentives to avoid wrongdoing in the first place and to sue for defamation are also likely to depend on the impacts the two legal rules have on the relative frequencies of type I and type II errors, i.e., on the key factor identified in our model. The same holds for the media's incentives to investigate and publish stories, and it also holds for its incentive to reveal anonymous sources as long as signaling effects are neglected. Integrating signaling effects in dynamic games with reputation is beyond the purpose of this paper, not only as it turns out to be rather convoluted, but mainly because we believe that the decisions of journalists to reveal anonymous sources are not mainly driven by considerations about the rational behavior of sources in Perfect Bayesian Equilibria in mixed strategies, but rather by the allocation of the burden of proof, the design of negligence and damages, reputation effects, and the corporate policy of newspapers. 
Reporter's Privilege and Incentives to Leak / 713

\section{Appendix}

\section{A. Proof of Result 1}

- Part (i) has already been proven in the text.

- Part (ii) (impact of $q$ ). The difference in social costs is then $\Delta \equiv \phi^{E}-\phi^{A}=$ $t q \pi(\pi+q(1-\pi))-\tau \pi(1-q)(1+w(1-\pi-q))$. Hence, $\frac{\partial \Delta}{\partial q}=\pi(1+2 w(1-q))+$ $\pi \tau(2 w-\pi w-2 q w+1)>0$. For $q \rightarrow 1, \Delta=\pi(\tau(1-\pi w)+1)>0$ which proves that the American rule is always superior when $q$ is sufficiently high. For the minimum $q=0.5,{ }^{8}$ however, the American rule is obviously inferior when type II errors are sufficiently important, i.e., for $\tau$ sufficiently high.

- Part (iii) (impact of $t$ ). From $\Delta$ as given in the proof of part (ii), we get $\frac{\partial \Delta}{\partial t}=\pi q(\pi+q-\pi q)>0$. For $t \rightarrow 0, \Delta=-\tau \pi(1-q)(1+w-w(\pi+q))<0$. For $t \rightarrow w$, $\Delta$ is positive if and only if $\tau<\frac{q w(\pi+q(1-\pi))}{(1-q)(1+w(1-\pi-q))}$.

\section{B. PROOF OF RESULT 2}

Under the English rule, expected social costs are

$$
\phi^{E} \equiv \phi_{1}^{E}+\phi_{2}^{E}=\pi t+(1-\pi t)(1-\pi)(1-q)+\tau(1-\pi w)(1-\pi)(1-q),
$$

which yields $\frac{\partial \phi^{E}}{\partial \pi}=q(1+t)+(1-q)(2 \pi(t+w \tau)-\tau(1+w))-1$ and $\frac{\partial^{2} \phi^{E}}{\partial \pi^{2}}=(1-q)(2 t+2 w \tau)>0$. If $\frac{\partial \phi^{E}}{\partial \pi}<0 \forall \pi$, which becomes more likely if $\tau$ is high, then $\pi^{E}=1$. When $\frac{\partial \phi^{E}}{\partial \pi}$ is increasing at $\pi=1$, the interior solution is $\pi^{E}=\frac{1-q+(\tau+w \tau)(1-q)-q t}{(1-q) 2(t+w \tau)}$.

Under the American rule, expected social costs are

$$
\phi^{A} \equiv \phi_{1}^{A}+\phi_{2}^{A}=(1-q) \pi t+(1-(1-q) \pi t)(1-q)(1-\pi)+\tau(1-q \pi w)(1-q)
$$

which yields $\frac{\partial \phi^{A}}{\partial \pi}=(1-q)(-q w \tau+q t+2 \pi t(1-q)-1)$ and $\frac{\partial^{2} \phi^{A}}{\partial \pi^{2}}=2 t(1-q)^{2}>0$. If $\frac{\partial \phi^{A}}{\partial \pi}<0 \forall \pi$, then $\pi^{A}=1$. When $\frac{\partial \phi^{A}}{\partial \pi}$ is increasing at $\pi=1$, the interior solution is $\pi^{A}=\frac{1-q t+q w \tau}{2 t(1-q)}$. Assuming interior solutions, we get

\footnotetext{
${ }^{8}$ Recall that for $q<0.5$, the court's quality is below the quality when throwing a dice, which would be a senseless assumption.
}

DOI: $10.2202 / 1555-5879.1367$ 


$$
\pi^{E}-\pi^{A}=\frac{(t \tau(1-q))(1+w)-w \tau(1+q w \tau)-q t}{2 t(t+w \tau)(1-q)}
$$

so that the sign depends on the numerator $N$. Since $\frac{\partial N}{\partial q}=-w^{2} \tau^{2}-t w \tau-t \tau-t<0$ and as $N=-w^{2} \tau^{2}-w \tau-t<0$ for $q=1$, we can restrict attention to the minimum $q=0.5$. Then, $N(q=0.5)=-0.5 t(1-\tau)-w \tau(1+0.5 w \tau-0.5 t)<0$ and thus $\pi^{E}-\pi^{A}<0 \forall q$.

\section{References}

Anderson, D. 1991. "Is Libel Law Worth Reforming?" 140 University of Pennsylvania Law Review 487-554.

Bar-Gill, O., and A. Hamdani. 2003. "Optimal Liability for Libel," 2(1) Contributions to Economic Analysis \& Policy.

Berlins, M. 2004. UK Is the Libel Capital of the World. available from: http://www.ifex.org/en/content/view/full/61064/.

Bernardo, A., E. Talley, and I. Welch. 2000. "A Theory of Legal Presumptions," 16(1) Journal of Law, Economics and Organization 1-49.

Bradley, I. 1996. Economic Aspects of Defamation Law and the Media. Public Sector Economics Research Centre, University of Leicester, http:/ideas.repec.org/p/lec/lpserc/96-7.html.

Browne, D. 2005. Libel and Publication in the Public Interest. Paper presented at the Law for Journalists Conference, http://www.5rb.co.uk/articles/detail.asp?ArticleID=2.

Bruns, A. 2000. "Access to Media Sources in Defamation Litigation in the United States and Germany," 10 Duke Journal of International and Comparative Law 283-306.

Cooter, R., and W. Emons. 2003. "Truth-Revealing Mechanisms for Courts," 159(2) Journal of Institutional and Theoretical Economics 259-279.

Dalvi, M., and J. Refalo. 2008. "An Economic Analysis of Libel Law," 34(1) Eastern Economic Journal 74.

Demougin, D., and C. Fluet. 2006. "Preponderance of Evidence," 50(4) European Economic Review 963-976.

Dent, C., and A. Kenyon. 2004. Defamation Law's Chilling Effect: A Comparative Content Analysis of Australian and US Newspapers. The University of Melbourne Faculty of Law, Legal Studies Research Paper No. 94.

Dienes, C., L. Levine, and R. Lind. 1999. Newsgathering and the Law. Lexis Law Pub.

Docherty, B. 2000. "Defamation Law: Positive Jurisprudence," 13 Harvard Human Rights Journal 263-287.

Garoupa, N. 1999a. "Dishonesty and Libel Law: The Economics of the 'Chilling' Effect," 155 Journal of Institutional and Theoretical Economics 284-300. . 1999b. "The Economics of Political Dishonesty and Defamation," 19(2) International Review of Law \& Economics 167-180.

Gatley, J. 2004. Law and Practice of Libel and Slander in a Civil Action, 10th edition. Sweet \& Maxwell. 
Gilles, S. 1998. "Taking First Amendment Procedure Seriously: An Analysis of Process in Libel Litigation," 58 Obio State Law Journal 1753-1808.

Hollander, D. 1989. "The Economics of Libel Litigation," in E. Dennis and E. Noam, eds. The Cost of Libel, 257-283. Columbia University Press.

Kenyon, A. 2004a. Imputation or Publication: The Cause of Action in Defamation Law. The University of Melbourne Faculty of Law, Legal Studies Research Paper No. 97. . 2004b. Lange and Reynolds Qualified Privilege: Australian and English Defamation Law and Practice. The University of Melbourne Faculty of Law, Legal Studies Research Paper No. 126.

Kirtley, J. 1996. "Vanity and Vexation: Shifting the Focus to Media Conduct," 4(3) William \& Mary Bill of Rights Journal 1069-1110.

Loveland, I. 2003. "The Ongoing Evolution of Reynolds Privilege in Domestic Libel Law," 14(7) Entertainment Law Review 178-183.

Marjoribanks, T., and A. Kenyon. 2004. Negotiating News: Journalistic Practice and Defamation Law in Australia and the US. The University of Melbourne Faculty of Law, Legal Studies Research Paper No. 67.

Polinsky, A., and S. Shavell. 1989. "Legal Error, Litigation, and the Incentive to Obey the Law," 5(1) Journal of Law, Economics, and Organization 99-108.

Rubinfeld, D., and D. Sappington. 1987. "Efficient Awards and Standards of Proof in Judicial Proceedings," 18(2) RAND Journal of Economics 308-318.

Sanchirico, C. 1997. "The Burden of Proof in Civil Litigation: A Simple Model of Mechanism Design," 17(3) International Review of Law \& Economics 431-447.

Sheer, A., and A. Zardkoohi. 1985. "Analysis of the Economic Efficiency of the Law of Defamation," 80 Northwestern University Law Review 364-475. and _. 1989. "Is the Law of Defamation Economically Efficient?" in E. Dennis and E. Noam, eds. The Cost of Libel, 207-227. Columbia University Press.

Shin, H. 1998. "Adversarial and Inquisitorial Procedures in Arbitration," 29(2) RAND Journal of Economics 378-405.

Teeter, D., D. Le Duc, and B. Loving. 2004. Law of Mass Communications. Foundation Press.

Weaver, R., and D. Partlett. 2004. "Defamation, the Media, and Free Speech: Australia's Experiment with Expanded Qualified Privilege," 36 George Washington International Law Review 377-431.

Williams, A. 1997. "England and Wales," in C. Campbell, ed. International Media Liability. Wiley \& Sons.

DOI: $10.2202 / 1555-5879.1367$ 